\section{DEAN AMONG 100 INFLUENTIAL FIGURES}

A professor from the University of Salford has made the Power List - a list of the UK's 100 most influential people of African or Afro-Caribbean heritage for the second year running.

Professor Cynthia Pine CBE, Executive Dean of the University's Faculty of Health \& Social Care, was among the 100 influential figures in a list that included the Archbishop of York Dr John Sentamu and Formula One driver Lewis Hamilton.

To celebrate the award, Professor Pine and other members of the list were invited to a reception hosted by Prime Minister, Gordon Brown.

Celebrating people in the UK with African heritage who have the ability to make a difference to people's lives, the Power List is broken down by sector, with Professor Pine being included in the Science, Medicine and Engineering category.
Professor Pine was acknowledged for her achievements and pioneering status after her appointment as the first female dean of a UK dental school since the first one opened 150 years ago, and her subsequent work as the Dean of Health At Social Care at Salford.

She also works with the World Health Organisation to tackle inequality in children's oral health. In 2006 she was appointed CBE in the Queen's Birthday Honours for her services to dentistry.

As well as these achievements, she is a consultant in dental public health at Salford Primary Care Trust. Professor Pine said, 'To make the Power List for the second time is a tremendous honour for me. I'm committed to the cause of improving people's health, and if awards such as this can help to draw attention to this, then I'm doubly pleased to be included.'

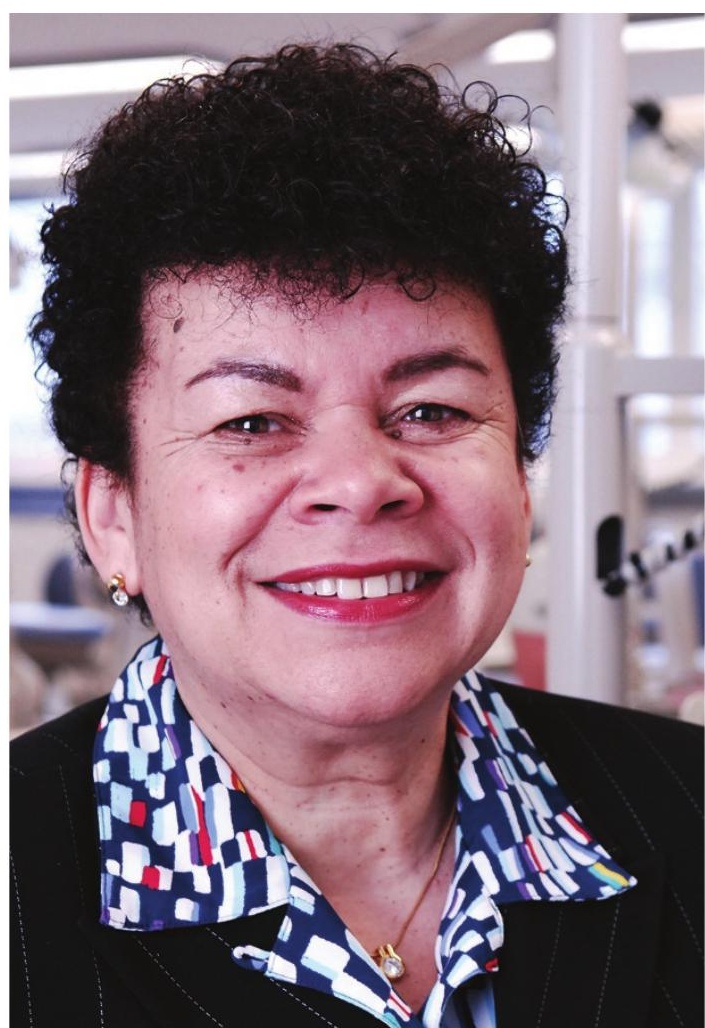

Cynthia Pine CBE

\title{
GUIDELINES HIGHLY COMMENDED
}

The British Orthodontic Society's (BOS) book BOS radiology guidelines was one of only four highly commended books out of 27 entries in the radiology category of the BMA Medical Book Awards which took place recently.

The BMA Medical Book Awards are presented annually and this year there were over 600 entries in a variety of categories. Each section is judged and awarded Winner, Highly Commended and Commended certificates.

The BMA citation for BOS radiology guidelines stated 'This is an excellent, well written and concise write-up on the background of clinical dental radiographs and indication for radiographs in clinical orthodontics. It is a must read for all clinical dentists especially those treating children.'

The guidelines were designed to assist the hospital practitioner, orthodontic specialist and the general dental practitioner on the choice and timing of radiographs in clinical orthodontic practice and reflect current best practice and selection criteria to comply with the IRMER requirements.
To emphasise the importance of the legislative requirements and to strengthen the sections of radiation safety, the guidelines were co-authored by experts in dental and maxillofacial radiology: Keith Isaacson, Consultant Orthodontist at North Hampshire Hospital in Basingstoke, Allan Thom, Consultant Orthodontist at Queen Victoria Hospital, East Grinstead, Professor Keith Horner, Professor of Oral and Maxillofacial Imaging at the School of Dentistry in Manchester, and Eric Whaites, Senior Lecturer and Honorary Consultant in Dental Radiology at Kings College London Dental Institute.

The book contains step-by-step information to help with assessment and treatment planning including four 'at a glance' charts which graphically illustrate the indications of when patients should or should not be subjected to radiographs.

For further information on the publication please visit the Society's website at www.bos.org.uk or copies can be obtained by telephoning 02073538680 .

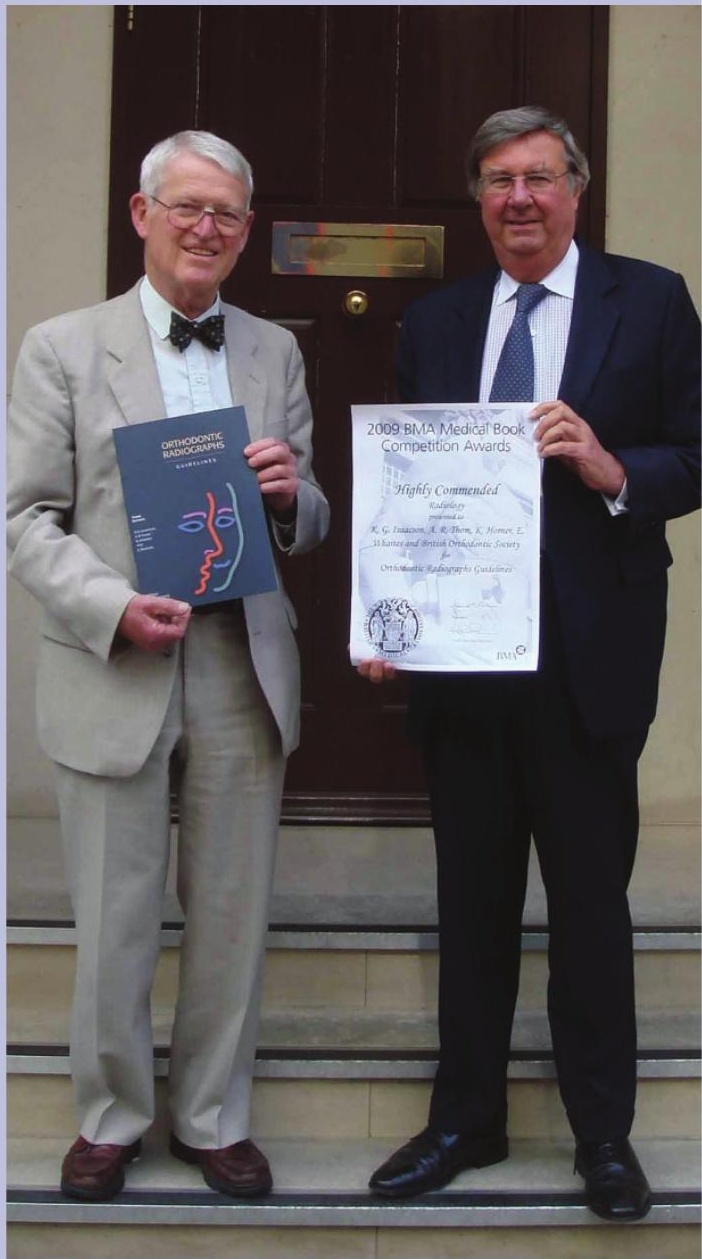

Keith Issacson and Allan Thom 